\title{
Writing the literature review for empirical papers
}

\author{
Davi Nakano ${ }^{\text {a* }}$, Jorge Muniz Jr. ${ }^{\text {b }}$ \\ aUniversidade de São Paulo (USP), São Paulo, SP, Brazil \\ bUniversidade Estadual Paulista (UNESP), Guaratinguetá, SP, Brazil \\ *dnnakano@usp.br
}

\begin{abstract}
Paper aims: The purpose of the paper is to offer guidance regarding how to write a Literature Review for empirical papers, that provides adequate background and convincing support. The literature review plays the fundamental role of unveiling the theory, or theories, that underpin the paper argument, sets its limits, and defines and clarifies the main concepts that will be used in the empirical sections of the text.

Originality: Most papers and books focus on literature review as full articles (systematic reviews, meta analyses and critical analyses) or dissertation, chapters, this paper is focused on literature review for an empirical article.
\end{abstract}

Research method: It is a theoretical essay.

Main findings: The paper summarizes the main steps for performing a literature review and guides how to organize the analyzed literature.

Implications for theory and practice: Well-crafted literature reviews are the cornerstone of good papers, and this paper offers some guidance on how to write good reviews for empirical papers, and, as a consequence, to produce better quality texts.

\section{Keywords}

Literature review. Metanalyses. Critical analyses. Empirical paper.

How to cite this article: Nakano, D., \& Muniz Jr., J. (2018). Writing the literature review for an empirical paper. Production, 28, e20170086. http://dx.doi.org/10.1590/0103-6513.20170086

Received: Oct. 24, 2017; Accepted: Jan. 22, 2018.

\section{Introduction}

As former editors of Production Journal, we have observed that one of the main reasons for the immediate rejection of a paper is what is generally referred as "lack of conceptual (or theoretical) contribution", i.e., when Editors/Referees are unable to identify which are the proposed additions to the theory authors wish to present in their texts. During 2015-2017 period, the Production Journal rejected 65\% of the submissions during the first screening process, mainly for missing theoretical contribution.

The quest for contribution rests on the principle that creating science is a collective and cumulative endeavour, in which each researcher builds upon previously developed knowledge by others, and presents her contribution to the field. The issue of how to make a contribution has already been addressed by several authors from the Organizational Theory field (Sutton \& Staw, 1995; Whetten, 2003), OM (Boer et al., 2015), and it will also be the subject of another paper in this journal, but we believe that weakness is not only related to the paper rationale, where the argument for contribution is developed, but also to how authors construct the theoretical background of their texts. A good literature review supports the paper assertion for contribution, and it is the cornerstone of a successful paper. Even when a paper does make a clear claim for conceptual contribution, it is not uncommon to find that the literature review section does not provide it a consistent foundation, weakening the whole paper, and frequently jeopardizing authors' efforts. In fact, the absence of a well-crafted theoretical background undermines any paper and wastes effort-intensive fieldwork. 
However, despite its importance, it seems that how to build the review of a body of literature is considered a simple, obvious task (Hart, 1998), and thus, there is actually few texts that delve into that effort. To make things harder, indications of how to build strong theory into a paper can be confusing, especially because authors have to deal with many trade-offs: comprehensiveness versus deepness, simplicity versus accuracy (Sutton \& Staw, 1995) and so on. However, there are a number of good references on how to write a literature review for two purposes: (a) as chapters of master theses and doctoral dissertations (e.g. Boote \& Beile, 2005; Hart, 1998), and (b) for literature reviews as full articles (e.g. Kitchenham et al., 2009; Tranfield et al., 2003; Thomé et al., 2016). This paper draws upon those contributions to suggest some guidelines for authors to write literature review sections for their empirical papers, and provide a convincing rationale to supports this effort, especially from the Operations Management (OM) point of view. It is structured as follows: it briefly presents the different strategies for writing literature reviews as full papers, and then discuss how to write the review section for an empirical paper, based particularly on the literature for theses and dissertations.

\section{Literature reviews as full articles}

Literature reviews are often presented as full papers, and there are journals which scope is focused on this genre, as the International Journal of Management Review, the Academy Management of Review and the Psychological Review. Reviews offer a comprehensive and thorough analysis of the academic production on a certain topic, and are very useful for both novice and experienced researchers. There are some strategies to build literature review articles: the meta-analysis (MA), the critical analysis (CA), and the integrative or systematic literature review (SLR).

MAs propose one or more research questions and to answer them, analyse large sets of articles on a subject, which authors, titles, keywords, abstracts and references are collected from academic portals and organized in a database. MAs perform statistical analyses on collected data, often using specific software (e.g. Citespace, VOSviewer, Sitkis, etc.), and present an aggregate description of how the academic output has evolved, which are the more prominent papers and authors, how they are connected by the citations they share, and how they answer the research questions. In that sense, MAs synthesize and present a comprehensive view of the literature, and, if the paper set is carefully assembled, offer an overall reliability that cannot be reached from other methods (Tranfield et al., 2003). MAs can be used as the first step for a SLR or a CA, or, for instance, to present a bird's eye picture of the literature in a dissertation. Many academic portals (Scopus, Web of Science, EBSCO, Science Direct, SciElo) and/or softwares support some level of MA, providing descriptive statistics on sets of papers, which can support further analysis. However, if there are no research questions to be discussed, descriptive statistics hardly ever present theoretical contributions per se, and MAs should offer, at minimum, a critique on the field and present opportunities for future research. For further study, Fink (1998, p. 216) offers a guide on how to write MAs (Seven Steps to a Meta-Analysis).

In a CA, authors examine the main concepts, ideas and relationships of an issue presented by the extant literature, provide a critique, and in several cases, offer research propositions or a framework for future analysis. A CA can summarize a body of literature, report on the evolution of a research field, or reconcile different research strands on the same topic. Generally, paper set selection is subjective, which departs it from MAs: the set of papers is collected by the writers, who decide both what to include and how those ideas will be discussed and summarized. In that sense, it does not intend to be exhaustive, authors are concerned to give the most accurate picture of the field from their point of view. But even in CAs, there are also paper sets defined by statistical sampling (e.g. Burgess et al., 2006). CAs can cover broad or narrow topics: for example, Anderson et al. (1989) provided an overview and an analysis on the literature on Operations strategy, while Ngai et al. (2008) delivered an analysis on the literature on RFID. They can discuss topics from few or several perspectives or lines of research: Rochet \& Tirole (2006) offered a report on the evolution of the knowledge on multi-sided markets and platforms, while Mills et al. (2004) reviewed the literature on supply networks. CA offers a view on the state-of-art of knowledge on a subject, provide analytical frameworks and indicate avenues for future research. CAs should follow the same quality principles as any research project, and some guidelines for a good CA are (Popay et al., 1998, 2006):

- Different sources and journals should be explored;

- The sample has to be selected in a purposeful way, guided and shaped by theory. It must give attention to the diverse contexts and meanings that the study is aiming to explore;

- Interpretation needs to follow a clear and explicit process;

- Claims and assertions must be logically supported, theoretically grounded and be amenable of generalization, i.e., they should be applicable in different contexts. 
The SLR is a form of research that reviews, critiques, and synthesizes representative literature on a topic in an integrated way, generating new frameworks and perspectives (Torraco, 2005), using a much larger paper set than a CA. It also departs from research questions and requires a great deal of skill and insight (Torraco, 2005), it is not just an aggregation of all existing evidence on a research question; it intends to provide evidence-based guidelines for researchers and practitioners. To Kitchenham et al. (2009) SLR is a literature survey with defined research questions, a clear search and data extraction process, and its presentation (detailed in Appendix). Tranfield et al. (2003) cite it as a replicable, scientific and transparent process that aims to minimize bias through an exhaustive literature search on published and unpublished studies, providing an audit trail of the reviewers decisions, procedures and conclusions. Thus, SLRs are related to locating, appraising and synthesizing evidence (Petticrew \& Roberts, 2006). SLRs entail a series of techniques for minimizing bias and error, and thus, SLRs and MAs are widely regarded as providing 'high-quality' evidence. The pros and cons of a SLR are indicated in Table 1.

Table 1. Pros and cons of a systematic literature review.

\begin{tabular}{ll}
\hline \multicolumn{1}{c}{ Pros } & \multicolumn{1}{c}{ Cons } \\
\hline Collection from a broad range of sources & Could limit creativity and intuition \\
Aids interdisciplinary as it highlights cross disciplinary themes & Could overlook important "grey literature" e.g. reports \\
lncrease transparency of review & Restricted to the accessibility of sources \\
lncreases replicability of the review & Keyword search strings need to be identifiable \\
Being "systematic" offers a sense of rigor & Relies on databases that support "keyword" search \\
Aids the process of synthesis through the increased scope possible & Relies on the quality of abstract (often limited to 100 words) \\
\hline
\end{tabular}

Source: Easterby-Smith et al. (2012, p. 109).

A SLR starts arguing the need for the review article, the importance of the problem or topic to be examined, and by justifying why a SLR is the appropriate way to address the problem. Then it selects and examines a body of literature, exposing its strengths and deficiencies, to create a better understanding of the topic through synthesis, by integrating existing and new ideas to create a new formulation for the topic or issue (Torraco, 2005, p. 362). Unlike a CA, in which authors review the literature from a personal perspective, a SLR makes the reviewing process as structured, transparent, replicable and exhaustive as possible (Torraco, 2005). In order to achieve these aims, a structured process must be followed to design and implement the paper database, from which it is possible to identify patterns and themes of various publications, as well as their frequency and occurrence. Data can provide evidence on changes, shifts and gaps of the literature. Three major phases are required to build a SLR: (i) planning, (ii) execution, and (iii) summarization/reporting. In the first phase, authors must identify the need for a review and create a review protocol' 1 . In the second, they should identify and select relevant primary studies, perform data extraction from paper databases and synthesize them. Finally, in the third phase, they should summarize and report the results. There are online manuals for performing MAs and SLRs (Higgins \& Green, 2011) and some guidelines to perform those phases are presented in (Kitchenham et al., 2009; Torraco, 2005).

Table 2 presents an overview of the three strategies and offers an analysis based on a representative example.

\section{The literature review in an empirical paper}

In this section we discuss the literature review as a part of an empirical article. It plays the fundamental role of unveiling the theory, or theories, that underpin the paper argument, or, if there are no such theoretical background, which is the related extant knowledge. It sets the limits of discussion, and defines and clarifies the main concepts that will be used in the empirical sections. A substantive and thorough literature review is the basis for any good research project (Boote \& Beile, 2005) and a well-crafted literature review section provides the theoretical foundation that is required to support any argument of contribution.

Theories are systems of concepts that "[...] explain facts and provide stories as to how phenomena work the way that they do [...]" (Boer et al., 2015, p. 1247), and the first task of a literature review is to reveal which theories are used in the paper's argument. Boer et al. (2015) propose that there are two fundamental ways to make a theoretical contribution: exploratory studies observe and identify interesting phenomena that are not yet well explained by extant literature and propose hypotheses, while confirmatory studies empirically test

\footnotetext{
Protocol is a document that presents an explicit scientific "road map", detailing the rational and planned methodological and analytical approach of the review (Shamseer et al., 2015, p. 3).
} 
Table 2. MA, CA and SLR Examples and Main Points.

\begin{tabular}{|c|c|c|c|c|}
\hline \multicolumn{2}{|c|}{ Technique } & Meta-analysis (MA) & Critical Analysis (CA) & Systematic Review (SR) \\
\hline & & $\begin{array}{l}\text { It uses statistical techniques to combine } \\
\text { and summarize results of multiple } \\
\text { studies; they may or may not be } \\
\text { contained within a systematic review }\end{array}$ & $\begin{array}{l}\text { lt is a "[...] critical evaluation of the } \\
\text { literature according to argument, logic } \\
\text { and/or epistemological tradition of } \\
\text { the review subject [...]" (Petticrew \& } \\
\text { Roberts, 2006, p. 19) }\end{array}$ & $\begin{array}{l}\text { It is a "[...] review that strives to } \\
\text { comprehensively identify, appraise and } \\
\text { synthesize all relevant studies on a } \\
\text { given topic [...]" (Petticrew \& Roberts, } \\
\text { 2006, p. 19) }\end{array}$ \\
\hline \multirow[b]{3}{*}{ Source } & $\begin{array}{l}\text { Author } \\
\text { Title }\end{array}$ & $\begin{array}{l}\text { Serenko \& Bontis (2004) } \\
\text { Meta review of knowledge management } \\
\text { and intellectual capital literature: Citation } \\
\text { impact and research productivity rankings }\end{array}$ & $\begin{array}{l}\text { Nonaka \& Peltokorpi (2006) } \\
\text { Objectivity and subjectivity in knowledge } \\
\text { management: a review of } 20 \text { top articles }\end{array}$ & $\begin{array}{l}\text { Perkmann et al. (2013) } \\
\text { Academic engagement and } \\
\text { commercialization: A review of the } \\
\text { literature on university-industry relations. }\end{array}$ \\
\hline & Objective & $\begin{array}{l}\text { The paper conducts a meta-review } \\
\text { analysis of knowledge management and } \\
\text { intellectual capital literatures }\end{array}$ & $\begin{array}{l}\text { The paper classifies the KM publications } \\
\text { relating subjectivity-objectivity. }\end{array}$ & $\begin{array}{l}\text { The paper proposes a theoretical } \\
\text { framework about academic scientists } \\
\text { relationship in industrial sector. }\end{array}$ \\
\hline & $\begin{array}{l}\text { Main } \\
\text { Points }\end{array}$ & $\begin{array}{l}\text { It indicates criteria to select papers, } \\
\text { variables to analysis and indices } \\
\text { 1t indicates contrasts among research } \\
\text { areas, researcher(s) or university/ } \\
\text { organization contribution ranking } \\
\text { lt Introduces research impact for a new } \\
\text { area }\end{array}$ & $\begin{array}{l}\text { It evidences the selection criteria and } \\
\text { publication profile } \\
\text { It discusses objectivity and subjectivity } \\
\text { in a contribution on Knowledge } \\
\text { Management } \\
\text { It indicates challenges and } \\
\text { recommendations to theory-building and } \\
\text { methodology }\end{array}$ & $\begin{array}{l}\text { It indicates variables relating the } \\
\text { topics of academic engagement and } \\
\text { commercialization (service) } \\
\text { lt presents an analytical framework } \\
\text { of external engagement by academic } \\
\text { researchers based on the literature review } \\
\text { lt presents an agenda for future research }\end{array}$ \\
\hline
\end{tabular}

those hypotheses and confirm, refute or expand them. Knowledge creation rests upon a cycle of testing and amending or refuting existing theory, and the first step to succeed in that task, is to provide a clear picture of the underlying or related theories that support the paper argument. The literature review section opens up the field, showing how the issue under study has been discussed and which are its main concepts, how they have been studied from different points of view and how the field has evolved over time, in order to synthesize them and identify theoretical lacunae. Thus, crafting the literature review section of a paper must be concerned with three goals: setting its theoretical background, identifying gaps in the literature, and defining the key concepts that will be used in the paper:

- Establishing the theoretical background: some research projects are related to a single theory, while others work with multiple theories - to set up the background is to position the paper within the theory or theories that support and are used in its argument. It is useful to balance classic texts, which have established the discussion, with contemporary references, that show the current state of the field. Although the number of references should not be the main concern, the analysis must be comprehensive and include what is most relevant, which is not usually obtained by discussing only a few authors. For instance Abbariki et al. (2017) used 84 references to built the theoretical background, and synthesized it in four sections: a relational perspective on workplace knowledge, Processing tacit knowledge, Contextual factors affecting employee collaboration in processing tacit knowledge and Collective learning routines;

- Identifying gaps: a theoretical gap refers to a missing point in our current knowledge on a subject, or to an improperly conducted discussion, and the literature review should point to it. Theoretical gaps can be identified based on three rationales: (a) incompleteness - the current literature have not still properly discussed the problem or phenomenon; (b) inadequacy - the extant literature has not yet incorporated different perspectives on the problem or phenomenon, and (c) incommensurability - what is currently known on a subject has taken a wrong path and the existing theoretical discussion is misguided and incorrect (Locke \& Golden-Biddle, 1997). Contemporary, recent references are very important to the contribution claim, as they provide topicality;

- Defining key concepts: all key concepts used in the paper arguments must be clearly defined, as well as how they relate to each other, if that is the case, based on previous work. However, a literature review should not limit itself to a list of concept and construct definitions (Sutton \& Staw, 1995), it should present how they interconnected and how they will be used to support the argument. (e.g. Abbariki et al. (2017) defined key concepts on the different perspectives of knowledge to support their study).

\section{Which are the main characteristics of a good literature review?}

A good literature review must address different requirements, covering the relevant literature and synthesizing it with clarity. A journal paper has usually length limitations, thus, the literature review section needs to limit itself to what is important to the argument. Dissertation guides and handbooks (e.g. Boote \& Beile, 2005) indicate the key features for a literature review, which are also applicable for papers: 
- Coverage - Relevant references must be covered by the text. It does not mean just citing lots of authors, but identifying and presenting the relevant literature, the main research strands, and building a framework where the paper can be positioned. It is like drawing a map in which key places are identified, and indicating where in that map the paper argument is located. The issue of length must be carefully addressed, and as a general rule, it is always better to have a deeper discussion on the topics the paper delves in, than a superficial overview of several arguments;

- Synthesis - A good literature review is not a just a long list of citations, it should summarize and connect relevant references. Synthesis is not just putting references and concepts together. It requires creativity to offer a fresh, new view on the topic, for instance a model or a framework, which reflects the unique knowledge developed by the author (Torraco, 2005). The synthesis can be presented in the form of questions or propositions that have to be either verified or answered by fieldwork. It can also propose a model or a framework, which will be tested or applied in the empirical sections of the paper;

- Rhetoric - The text must be clear and coherent, ideas must be presented in a well-articulated text, which does not make unsupported assertions;

- Significance - The review also must show which is the practical and theoretical significance of the research problem. We strongly recommend that research problem should evidence theoretical aspects and also register organizational contributions as observed in Abbariki et al. (2017), which indicated the core of significance in paper' introduction.

A good literature review balances "[...] appropriate breadth and depth, rigor and consistency, clarity and brevity [...]" (Hart, 1998, p. 2), making an effective analysis and synthesis of the identified literature. Consistency and clarity are essential, as they support a coherent argument, while depth and rigor show how authors master the subject, providing a well-developed argument. Finally, brevity is also essential, as all relevant literature must be presented, analysed and articulated in a limited space. When one finishes reading the literature review, one should be able to answer the following questions:

- What are the main sources on the subject under study?

- Which are the key theories and ideas that support the paper's assertions?

- How the paper argument relates to a major issue or debate on the topic?

- What are the key concepts of the paper's argument and how are they are defined?

\section{How to write a literature review for empirical papers?}

Novice researchers may find the task of writing the literature review a quite overwhelming task after reading this paper to this point. To offer some practical steps to start it, we suggest that the researcher starts with a preliminary CA. To perform it, we suggest starting with a small set of 8 to 10 papers. To select papers, talking to supervisors and seasoned researchers is always the first action to take. Also, papers can be obtained from academic portals, such as Web of Knowledge, Scopus, Science Direct, EBSCO, JSTOR, SciELO, which strengths and weaknesses are indicated in Table 3. As each portal has its selection of sources, it may be convenient to search in more than one to get better coverage. Also, portals usually rank papers by number of citation/relevance, which is useful to identify fundamental papers and authors. However, it is important to remember that the older the paper, the greater the probability of citation, so if only number of citations is considered, one may end up with an older, and sometimes out-dated, set of papers. Finally, that paper set is just a preliminary selection, which needs to be refined as the researcher keeps studying the subject, and she will find that citations from papers are always a good source for further reading.

After assembling the initial set of papers, the aims, research questions, methods, findings, limitations and suggestions for future research can be extracted from each paper. Empirical papers usually are structured in at least five sections: (1) introduction, (2) literature review, (3) empirical methods, (4) data analysis, discussion and findings, and (5) conclusions. The introduction section usually presents the paper's aim, the theoretical gaps it addresses and its research questions, and the conclusion section discuss its limitations and opportunities for future research. Thus, reading first those sections usually helps to better grasp the whole paper.

After reading each paper, we suggest to summarize data in a table, as recorded in the Appendix (Authors, Objective, Findings, Research-questions, Further Research, Limitations, Methodology, Practical Implications). For further study, Perkmann et al. (2013, p. 434-439) applied similar strategy to summarize 133 articles, recording them in a table with the following columns: Research questions, Data Method, Dependent variables, and Findings. 
Table 3. Overview of sources.

\begin{tabular}{|c|c|c|c|}
\hline Source & Example & Strengths & Weaknesses \\
\hline Library & & $\begin{array}{l}\text { A lot of information available in } \\
\text { hardcopy, special literature can be } \\
\text { ordered }\end{array}$ & $\begin{array}{l}\text { Time consuming, often basic } \\
\text { knowledge and not the latest research } \\
\text { in the field }\end{array}$ \\
\hline $\begin{array}{l}\text { Selection-by-algorithm } \\
\text { platforms, without inclusion } \\
\text { criterion }\end{array}$ & Google Scholar & $\begin{array}{l}\text { Quick and easily accessible, easy to get } \\
\text { an overview of a topic }\end{array}$ & $\begin{array}{l}\text { It broadens the field and put the risk of } \\
\text { losing focus, it does not always shows } \\
\text { the relevant articles }\end{array}$ \\
\hline $\begin{array}{l}\text { Restricted access, full text } \\
\text { platforms, with inclusion } \\
\text { criteria }\end{array}$ & $\begin{array}{l}\text { Web of Science, Scopus, } \\
\text { EBSCO, JStor }\end{array}$ & $\begin{array}{l}\text { Focused search on author/journal/ } \\
\text { topics }\end{array}$ & $\begin{array}{l}\text { Papers are just available for individuals } \\
\text { or institutions which pay fees or have } \\
\text { access to periodicos.capes.gov.br }\end{array}$ \\
\hline $\begin{array}{l}\text { Open access, full text } \\
\text { platforms, with inclusion } \\
\text { criteria }\end{array}$ & SciELO, RedALyC, SPELL & Open Access & $\begin{array}{l}\text { Mainly Brazilian and Latin American } \\
\text { academics Journals are available }\end{array}$ \\
\hline $\begin{array}{l}\text { Social network academic } \\
\text { platforms, without inclusion } \\
\text { criteria }\end{array}$ & Research Gate & Direct contact with authors & $\begin{array}{l}\text { Some papers are not accessible because } \\
\text { of copyright issues. } \\
\text { Some authors may not return contact }\end{array}$ \\
\hline Special Interest Groups & & $\begin{array}{l}\text { The latest research, ideas sharing and } \\
\text { feedback }\end{array}$ & Accessible through most universities \\
\hline
\end{tabular}

Source: adapted from Easterby-Smith et al. (2012).

From this initial step, the author can assess if there is good coverage, which papers support the claims that will be made, and which present concept definitions. At this point, the author will realize which are subjects need to be further studied, and will start a new round of paper search and reading. It is a cyclical process, and ideally, in each cycle a clearer and deeper perspective is reached.

As academic output is huge and keeps growing literally everyday, there is the danger of losing focus and the researcher must be cautious about when to finish the literature search, as sometimes one is tempted to keep looking for more texts. Here again, guidance from supervisors and help from seasoned researchers is always a good way to check is the required coverage and deepness has been reached. Finally, the researcher must sum up her work on a text, which must offer a good synthesis and good rhetoric. Novice researchers will find that the first draft is never a good text, and a well-crafted piece of writing is the outcome of several revisions. Figure 1 summarizes the main steps for performing a literature review:

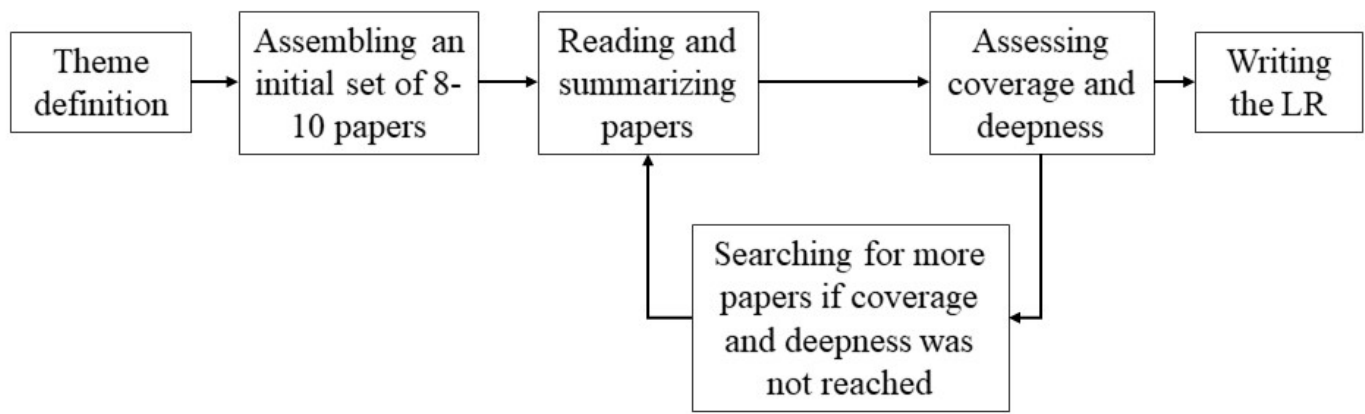

Figure 1. Steps for a LR.

\section{Conclusions}

Well-crafted literature reviews are the cornerstone of good papers, however it is not uncommon to find weak, or even absent, literature reviews among OM submissions to Production. That weakness jeopardizes any claim for contribution authors might have, and frequently undermines all effort put into fieldwork and data analysis. However, as an applied field, research in OM should not start exclusively from theory, practice has been and should continue to be a major source for research (Boer et al., 2015). Interesting, real world phenomena should motivate us to study and solve them, but our efforts should be aimed towards not only its solution, but also to how it can be generalized. There is no contribution case that stands the lack of a proper literature review and we hope to have offered some guidance on how to write good reviews for empirical papers, and, as a consequence, to produce better quality texts. 


\section{References}

Abbariki, M., Snell, R. S., \& Easterby-Smith, M. (2017). Sharing or ignoring tacit knowledge? A comparison of collective learning routines at two sites. Journal of General Management, 42(5), 57-67. http://dx.doi.org/10.1177/0306307017702997.

Anderson, J. C., Cleveland, G., \& Schroeder, R. G. (1989). Operations strategy: a literature review. Journal of Operations Management, 8(2), 133-158. http://dx.doi.org/10.1016/0272-6963(89)90016-8.

Boer, H., Holweg, M., Kilduff, M., Pagell, M., Schmenner, R., \& Voss, C. (2015). Making a meaningful contribution to theory. International Journal of Operations \& Production Management, 35(9), 1231-1252. http://dx.doi.org/10.1108/1JOPM-03-2015-0119.

Boote, D. N., \& Beile, P. (2005). Scholars before researchers: on the centrality of the dissertation literature review in research preparation. Educational Researcher, 34(6), 3-15.

Burgess, K., Singh, P. J., \& Koroglu, R. (2006). Supply chain management: a structured literature review and implications for future research. International Journal of Operations \& Production Management, 26(7), 703-729. http://dx.doi.org/10.1108/01443570610672202.

Easterby-Smith, M., Thorpe, R., \& Jackson, P. R. (2012). Management research. London: Sage.

Fink, A. (1998). Conducting research literature review: from paper to the internet. London: Sage.

Hart, C. (1998). Doing a literature review. London: Sage Publications.

Higgins, J. P. T., \& Green, S. Cochrane handbook for systematic reviews of interventions, version 5.1.0. 2011. Retrieved in 2017, December 4 , from http://handbook-5-1.cochrane.org/

Kitchenham, B., Pearl Brereton, O., Budgen, D., Turner, M., Bailey, J., \& Linkman, S. (2009). Systematic literature reviews in software engineering: a systematic literature review. Information and Software Technology, 51(1), 7-15. http://dx.doi.org/10.1016/j. infsof.2008.09.009.

Locke, K., \& Golden-Biddle, K. (1997). Constructing opportunities for contribution. Academy of Management Journal, 40(5), 10231062. http://dx.doi.org/10.2307/256926.

Mills, J., Schmitz, J., \& Frizelle, G. (2004). A strategic review of “supply networks". International Journal of Operations \& Production Management, 24(10), 1012-1036.

Ngai, E. W. T., Moon, K. K. L., Riggins, F. J., \& Yi, C. Y. (2008). RFID research: an academic literature review (1995-2005) and future research directions. International Journal of Production Economics, 12(2), 510-520. https://doi.org/10.1016/j.ijpe.2007.05.004.

Nonaka, l., \& Peltokorpi, V. (2006). Objectivity and subjectivity in knowledge management: a review of 20 top articles. Knowledge and Process Management, 13(2), 73-82. http://dx.doi.org/10.1002/kpm.251.

Perkmann, M., Tartari, V., McKelvey, M., Autioa, E., Broströmc, A., D’Este, P., Finif, R., Geuna, A., Grimaldif, R., Hughes, A., Krabel, S., Kitsong, M., Llerenai, P., Lissoni, F., Salter, A., \& Sobrerof, M. (2013). Academic engagement and commercialisation: a review of the literature on university-industry relations. Research Policy, 42(2), 423-442. http://dx.doi.org/10.1016/j.respol.2012.09.007.

Petticrew, M., \& Roberts, H. (2006). Systematic reviews in the social sciences: a practical guide. Malden MA: Blackwell.

Popay, J., Roberts, H., Sowden, A., Petticrew, M., Arai, L., Rodgers, M., \& Duffy, S. (2006). Guidance on the conduct of narrative synthesis in systematic reviews. A product from the ESRC methods programme Version, 1, b92. Retrieved in 2017, July 9, from https://www. researchgate.net/profile/Mark_Rodgers4/publication/233866356_Guidance_on_the_conduct_of_narrative_synthesis_in_systematic_ reviews_A_product_from_the_ESRC_Methods_Programme/links/02e7e5231e 8 f3a6183000000/Guidance-on-the-conduct-of-narrativesynthesis-in-systematic-reviews-A-product-from-the-ESRC-Methods-Programme.pdf

Popay, J., Rogers, A., \& Williams, G. (1998). Rationale and standards for the systematic review of qualitative literature in health services research. Qualitative Health Research, 8(3), 341-351. PMID: 10558335. http://dx.doi.org/10.1177/104973239800800305.

Rochet, J., \& Tirole, J. (2006). Two-sided markets: a progress report. The RAND Journal of Economics, 37(3), 645-667.

Serenko, A., \& Bontis, N. (2004). Meta-review of knowledge management and intellectual capital literature: citation impact and research productivity ranking. Knowledge and Process Management, 11(3), 185-198. http://dx.doi.org/10.1002/kpm.203.

Shamseer, L., Moher, D., Clarke, M., Ghersi, D., Liberati, A., Petticrew, M., Shekelle, P., \& Stewart, L. A. (2015). Preferred reporting items for systematic review and meta-analysis protocols (PRISMA-P) 2015: elaboration and explanation. BMJ (Clinical Research Ed.), 349 , g7647. PMid:25555855.

Sutton, R. 1., \& Staw, B. M. (1995). The relationship between integrating sphere and diffusion theory calculations of fluence rate at the wall of a spherical cavity. Administrative Science Quarterly, 4O(3), 1-12. PMid:7708833. http://dx.doi.org/10.2307/2393788.

Thomé, A. M. T., Scavarda, L. F., \& Scavarda, A. J. (2016). Conducting systematic literature review in operations management. Production Planning and Control, 27(5), 408-420. http://dx.doi.org/10.1080/09537287.2015.1129464.

Torraco, R. J. (2005). Writing integrative literature reviews: guidelines and examples. Human Resource Development Review, 4(3), 356367. http://dx.doi.org/10.1177/1534484305278283.

Tranfield, D., Denyer, D., \& Smart, P. (2003). Towards a methodology for developing evidence-informed management knowledge by means of systematic review. British Journal of Management, 14(3), 207-222. http://dx.doi.org/10.1111/1467-8551.00375.

Whetten, D. (2003). 0 que constitui uma contribuição teórica?. Revista de Administração de Empresas, 43(3), 69-73. 


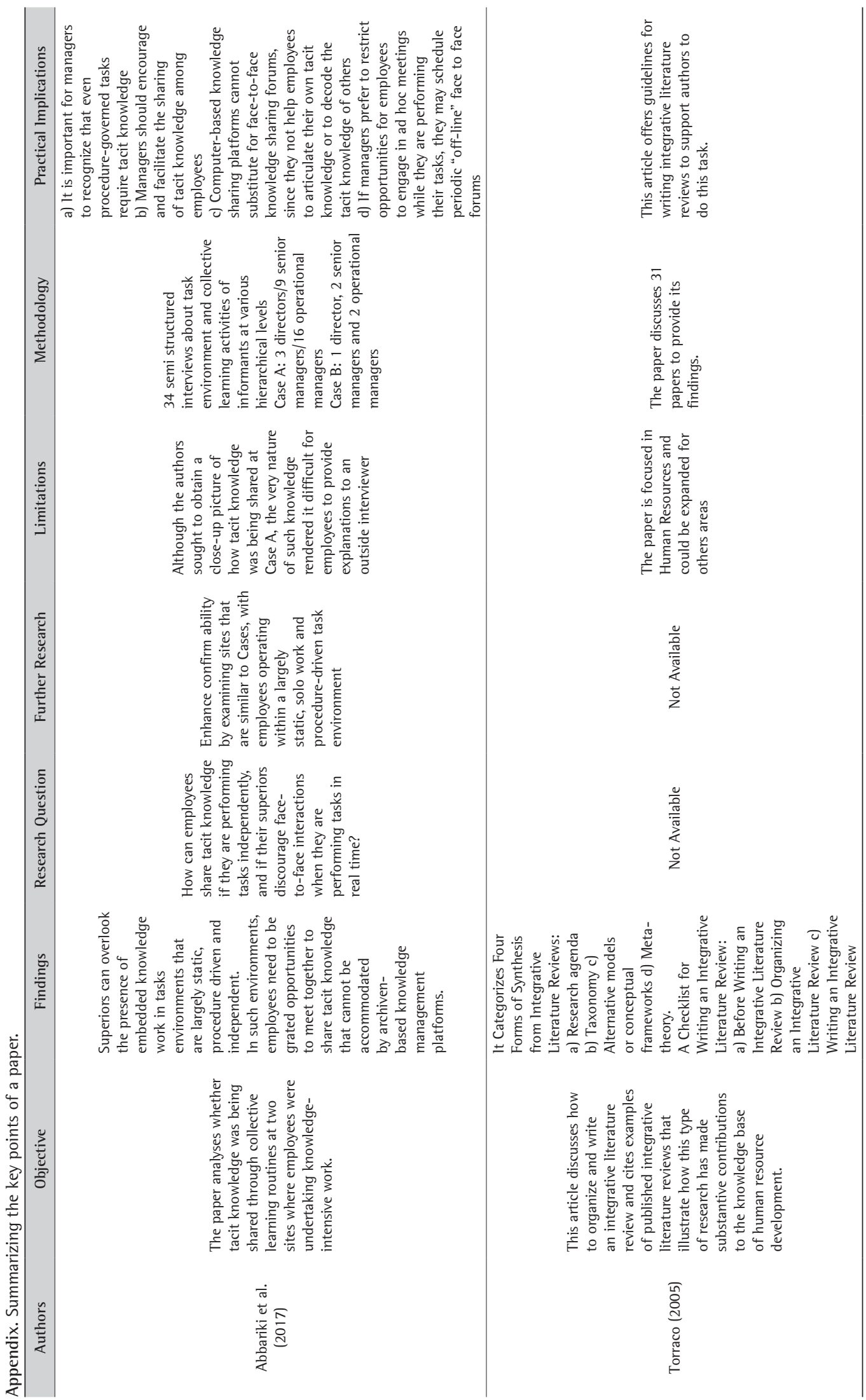




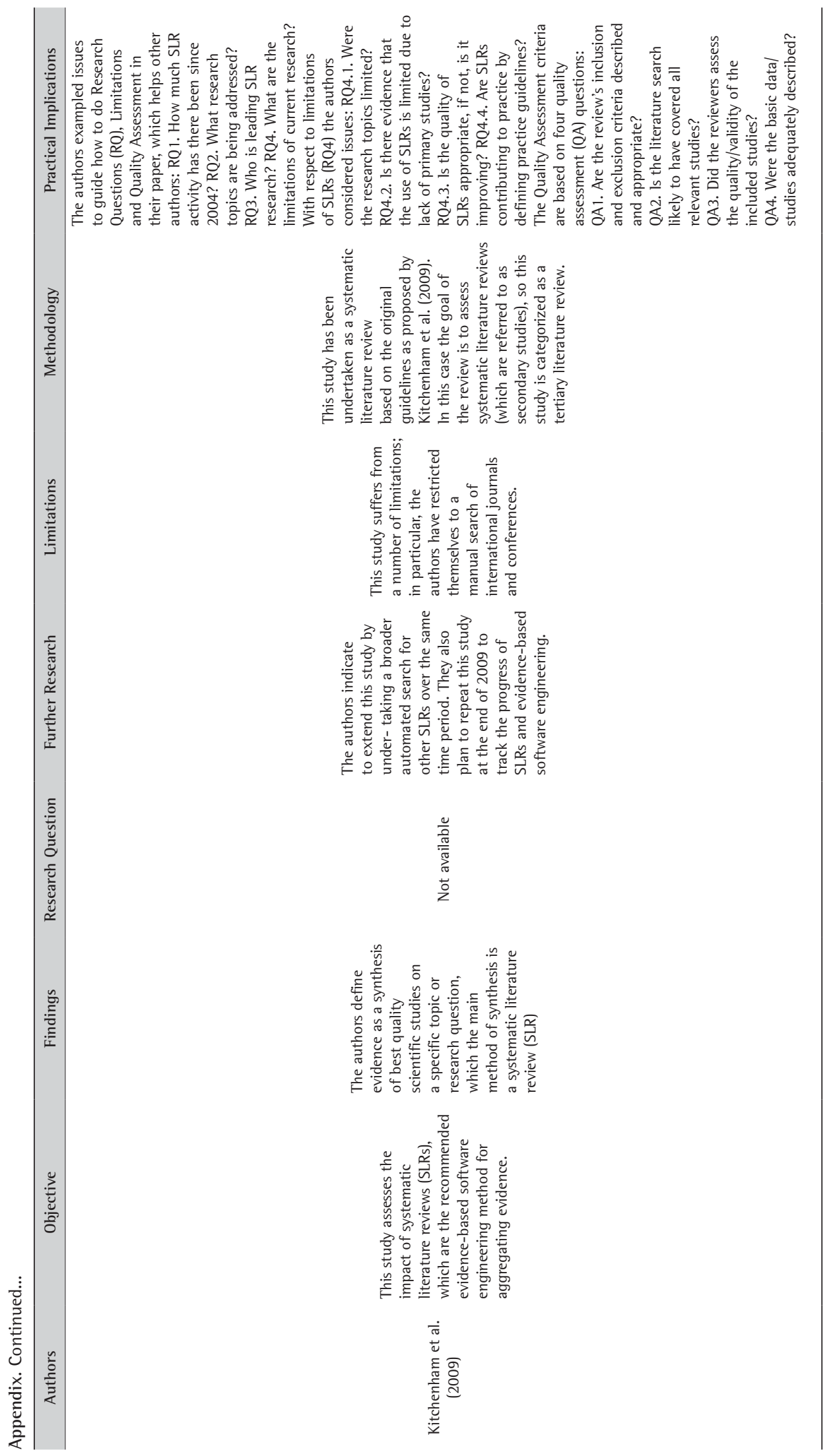

